\title{
Adrenal Pathophysiology: Lessons from the Carney Complex
}

\author{
Lionel Groussin Laure Cazabat Fernande René-Corail Eric Jullian \\ Jérôme Bertherat
}

INSERM U 567, CNRS UMR 8104, Université René-Descartes Paris V, Institut Cochin, Paris, France

\section{Key Words \\ Carney complex $\cdot$ Primary pigmented nodular adrenocortical disease $\cdot$ Cushing's syndrome $\cdot$ Cyclic AMP $\cdot$ PRKAR1A gene}

\begin{abstract}
The Carney complex (CNC) is a dominantly inherited syndrome responsible mainly for spotty skin pigmentation (lentiginosis), endocrine overactivity, and cardiac myxomas. Adrenocorticotropic hormone independent Cushing's syndrome due to primary pigmented nodular adrenocortical disease (PPNAD) is a main characteristic of CNC. PPNAD is a very rare cause of Cushing's syndrome due to a primary bilateral adrenal defect that can be also observed in some patients without other CNC manifestations nor familial history. One of the putative CNC genes, located on 17q22-24, has been identified as the regulatory subunit $\mathrm{R} 1 \mathrm{~A}$ of protein kinase $A$ (PRKAR1A). Heterozygous inactivating mutations of PRKAR1A have been reported initially in about $45 \%$ of the CNC index cases and could be found in about $80 \%$ of the CNC families presenting mainly with Cushing's syndrome. PRKAR1A is a key component of the cyclic AMP signaling pathway that has been implicated in endocrine tumorigenesis and could, at least partly, function as a tumor suppressor gene. Interestingly, patients with isolated PPNAD and no familial history of CNC can also present a germline de novo mutation of $P R K A R 1 A$. Somatic mutations of PRKAR1A have been found in PPNAD
\end{abstract}

as a mechanism of inactivation of the wild-type allele, in a patient already presenting a germline mutation, and in a subset of sporadic secreting adrenocortical adenomas with clinical, hormonal, and pathological features quite similar to PPNAD. This review will summarize the recent findings on CNC from the perspective of the pathophysiology of adrenal Cushing's syndrome and PPNAD.

Copyright $(2005$ S. Karger AG, Basel

\section{Introduction}

The Carney complex (CNC; MIM 160980) was first described in 1985 by J. Aidan Carney and coworkers [1] at the Mayo Clinic as the complex of myxomas, spotty pigmentation, and endocrine overactivity. The identification of this rare syndrome came from the study of 4 patients with an unusual cause of Cushing's syndrome published 1 year earlier as 'primary pigmented nodular adrenocortical disease' (PPNAD) [2]. By the analysis of the literature on similar cases of this rare cause of Cushing's syndrome, the association with cardiac myxomas in the same family led to the speculation of a connection between these two rare disorders. The first description of CNC included 40 patients [1], among them 10 familial cases, leading to the hypothesis of a genetic origin, at least in a subset of patients. PPNAD is a rare cause of adrenocorticotropic hormone (ACTH) independent Cushing's syndrome, occurring mainly in children and young adults. It could be diagnosed in no more than $1 \%$ of the patients

\section{KARGER \\ Fax +4161306 1234 E-Mail karger@karger.ch} www.karger.com
(C) 2005 S. Karger AG, Basel 0301-0163/05/0643-0132\$22.00/0

Accessible online at: www.karger.com/hre
Prof. Jérôme Bertherat

Département d'Endocrinologie, Métabolisme et Cancer, Institut Cochin

24, rue du Faubourg Saint-Jacques, FR-75014 Paris (France)

Tel. +33158411895, Fax +33146338060

E-Mail jerome.bertherat@cch.ap-hop-paris.fr 


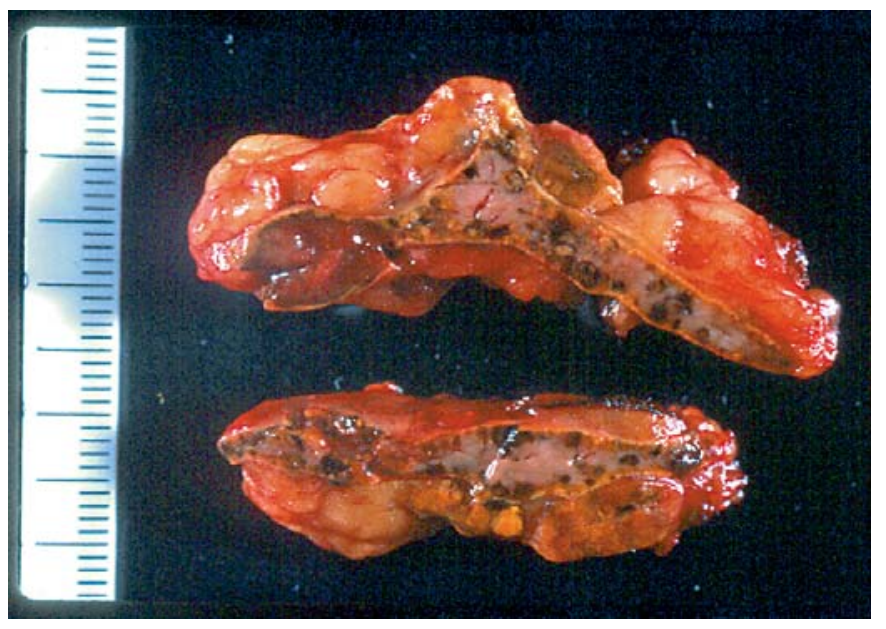

Fig. 1. PPNAD: macroscopic appearance of the adrenal gland. The cut surfaces show multiple pigmented micronodules. The periadrenal fat is also visible around the adrenal capsule.

with Cushing's syndrome. The name was given after the macroscopic appearance of the adrenals that is characteristic with small pigmented micronodules observed in the cortex (fig. 1). The disease is usually bilateral with primary involvement of both adrenals.

One of the first case reports of Cushing's syndrome due to PPNAD might have been published more than 50 years ago [see 3]. However, it was first reported as a specific entity in the late 60s [4]. Meador et al. [4] described a 14-year-old patient with dexamethasone-unsuppressible 17-hydroxycorticosteroid levels and undetectable plasma ACTH levels, even after adrenalectomy. The term 'primary adrenocortical nodular dysplasia' was used to describe the adrenal pathology with numerous black nodules $<2 \mathrm{~mm}$ in diameter 'resembling metastatic melanoma'. Several cases of Cushing's syndrome with micronodules in the adrenal cortex were reported by others during the same period $[5,6]$. Severe osteopenia in 2 young adults (19 and 23 years old) with Cushing's syndrome due to micronodular adrenal disease was reported shortly after by Ruder et al. [7]. The detailed and current description of PPNAD was established with the description of the CNC [1-3]. Analysis of families with CNC suggested that this disease can be part of a dominantly inherited syndrome. This hypothesis was initially investigated by linkage analysis by Stratakis et al. [8], leading to the identification of at least two loci. The identification of one of the CNC genes (CNC1: PRKAR1A) proved this concept and gives new insight into the pathophysiology of
PPNAD and adrenocortical tumors [9, 10]. PPNAD can typically be seen in patients with CNC, but is also definitely diagnosed in some patients without other CNC manifestations or familial history. The recent progress in the genetics of $\mathrm{CNC}$ raised the question of a unique or multiple pathophysiology and genetics of PPNAD and whether it might be a unique disease or whether it could be observed as various subcategories of diseases, as discussed later in this review.

\section{Clinical, Hormonal, and Imaging Investigations of PPNAD}

\section{Main Clinical Characteristics of PPNAD}

Cushing's syndrome due to PPNAD is observed in children and young adults. The peak age seems to be during the 2 nd decade [3]. It is rare but may occur before the age of 4 years, and it is rarely diagnosed after the age of 40 years, even by systematic screening of patients with known CNC. The diagnosis of Cushing's syndrome in PPNAD is often difficult because hypercortisolism can develop progressively over years. By contrast, in some patients rapid intense bursts of cortisol excess can be observed that might spontaneously regress. One of the first cases of PPNAD observed at the Mayo Clinic, in dizygotic twins just before World War II, had undergone spontaneous remission [3]. In some cases of PPNAD cyclic hypercortisolism has been documented [11-13]. The variations of the hypercortisolism observed in these patients with cyclic Cushing's syndrome and low ACTH plasma levels, without obvious tumor on adrenal computed tomography scan, can lead to the suspicion of exogenous glucocorticoid administration by proxy in a child. Cushing's syndrome due to PPNAD occurring during pregnancy has also been observed [14]. An in vitro stimulation of cortisol secretion by estradiol in a dosedependent manner was reported after culture of PPNAD tissue from a patient with Cushing's syndrome that was present during pregnancy and during oral contraceptive use [14]. PPNAD can now also be diagnosed by systematic screening of patients with $\mathrm{CNC}$, investigated for other clinical manifestations of the complex, or by familial screening. The mean time between the first symptoms and the diagnosis was about 4 years in historical series [3]. Despite the unusual time course of Cushing's syndrome that can be observed in some patients with PPNAD, clinical signs are quite similar to the observations made in patients presenting with other causes of hypercortisolism $[3,12,15]$. Central obesity and weight gain are the 
Fig. 2. Adrenal computed tomography scans in PPNAD: Adrenocortical micronodules are hardly detectable on both adrenals (arrows) in the scan shown on the left. A micronodule is visible on the external part of the left adrenal in the scan shown on the right (arrow).
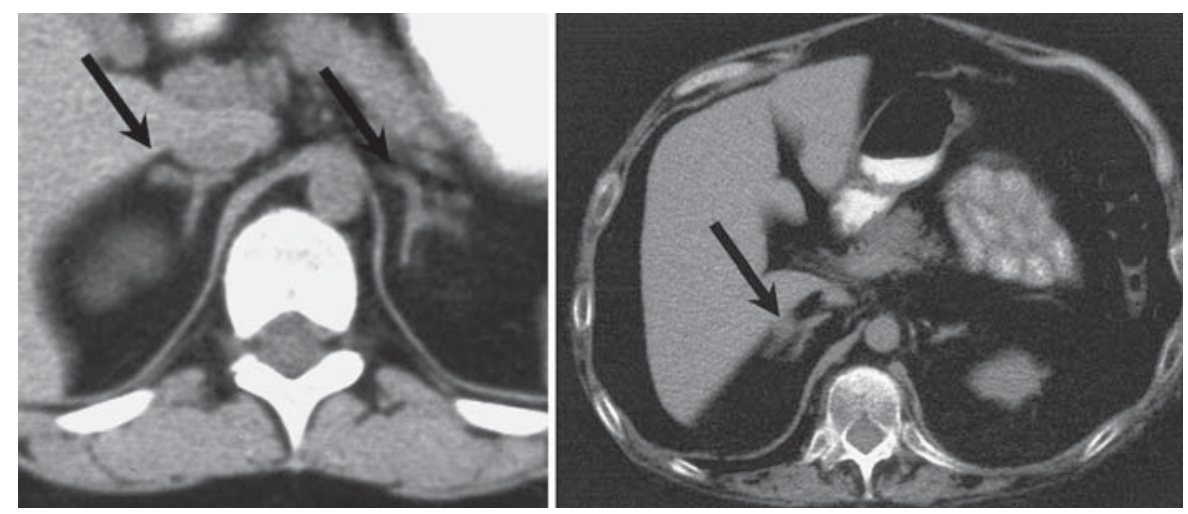

main features observed in most patients. Signs of increased catabolism such as purple striae, easy bruising, and muscular weakness are also frequent. Due to the occurrence of Cushing's syndrome in children, a short stature was observed in 29\% of the 72 patients reported by Carney and Young [3]. However, pediatricians should be aware that growth arrest is not a constant finding in children with PPNAD. This could be explained in some cases by cyclic hypercortisolism. It could be postulated that simultaneous growth hormone dysregulation due to somatotroph hyperplasia or an adenoma in patients with CNC might also protect at least partly from the consequences of cortisol excess during growth. Osteoporosis is also frequently observed and can constitute a long-term consequence of Cushing's syndrome, especially in patients in whom the diagnosis of PPNAD was delayed. Another difficulty in the diagnosis of PPNAD in children is the possibility of pseudoprecocious puberty or hirsutism, which are due to adrenal overactivity, but can sometimes be misdiagnosed as precocious puberty due to gonadal autonomy.

\section{Hormonal Investigations in PPNAD}

The urinary cortisol concentration is increased in most patients at the time of diagnosis of PPNAD, but its level can be highly variable $[11,12]$. The circadian rhythm of cortisol is usually completely abolished. As for other causes of ACTH-independent Cushing's syndrome, the plasma levels of ACTH are suppressed in patients with PPNAD. A classical biological feature of PPNAD is the discrepancy between a low plasma ACTH level and salivary or plasma cortisol concentrations remaining in the normal range or above. There is no stimulation of cortisol or ACTH after corticotropin-releasing hormone stimulation. In the same line, dexamethasone fails to suppress cortisol, even during high-dose administration. Interest- ingly, a paradoxical rise in the urinary cortisol level can be observed after dexamethasone treatment, particularly under high-dose administration (8 mg/day) [11]. This could be helpful in the diagnosis of PPNAD, especially in patients with normal basal urinary cortisol levels [16]. An increase of urinary cortisol of at least 100\% seems quite specific for PPNAD. This stimulatory effect of a glucocorticoid can be observed during primary culture of PPNAD tissues in vitro. Interestingly, this in vitro effect of dexamethasone increases with a longer exposure, suggesting a positive autostimulating feedback loop of glucocorticoids in PPNAD. An increased glucocorticoid receptor expression has been observed in pigmented nodules of PPNAD patients and could take part in this dysregulation [16]. By immunohistochemistry, a high level of glucocorticoid receptor expression can be observed in the cytoplasm of cells located in the nodules. We have also made the same observation for the progesterone receptor [Raffin-Sanson and Bertherat, unpubl.]. Therefore, alterations of the cortisol secretion by various steroids could be a general phenomenon in PPNAD. This observation could be related to the finding discussed above of Cushing's syndrome worsening during pregnancy in PPNAD and may be, in some cases, apparent transient hypercortisolism of pregnancy.

\section{Imaging of PPNAD}

At pathological investigation, adrenal glands from patients with PPNAD are usually normal in size and weigh between 4 and $17 \mathrm{~g}$ [3]. In keeping with these findings, the adrenals can appear normal on computed tomography scanning in 1 out of 3 patients. In the other patients, micronodules can be visible and, more rarely, macronodules ( $>1 \mathrm{~cm}$ in diameter) (fig. 2) in one or both glands [12]. Iodocholesterol scintigraphy, when performed, usually 
Table 1. Main features of $\mathrm{CNC}$

\begin{tabular}{ll}
\hline PPNAD $^{\mathrm{a}}$ & $25-45 \%$ \\
Cardiac myxoma $^{\mathrm{a}}$ & $30-72 \%$ \\
Skin myxoma $^{\text {Lentiginosis }}{ }^{\mathrm{a}}$ & $63 \%$ \\
Breast ductal adenoma $_{\text {Testicular tumors (LCCSCT = large-cell }}$ & $62 \%$ \\
$\quad$ calcifying Sertoli cell tumor) & \\
Ovarian cyst & $25 \%$ \\
Acromegaly & $56 \%$ \\
Thyroid tumor & $67 \%$ \\
Melanotic schwannoma & \\
Osteochondromyxoma $^{\mathrm{a}}$ & $10 \%$ \\
& $10 \%$ \\
\end{tabular}

Frequencies are given according to Carney et al. [1], Carney and Young [3], Stratakis et al. [8], and Kirschner et al. [18] and our personal observations.

${ }^{a}$ Manifestations of the disease that can be commonly observed in children younger than 10 years.

shows a bilateral uptake despite ACTH suppression by endogenous hypercortisolism.

\section{Therapy of PPNAD}

Treatment of Cushing's syndrome due to PPNAD is most often bilateral adrenalectomy. Some rare cases have been treated by mitotane, ketoconazole, or unilateral adrenalectomy. In the rare patients in whom overt Cushing's syndrome did not recur after unilateral adrenalectomy, alterations of the dynamics of cortisol secretion could be observed on long-term follow-up, demonstrating that despite apparent cure the disease is indeed bilateral [17]. This observation could be related to the finding of an abnormal adrenocortical function observed in relatives of patients with CNC and no obvious Cushing's syndrome. Therefore, the spectrum of cortisol dysregulation in PPNAD might be much broader than suggested when searching only for evident clinical signs of hypercortisolism. Similarly, PPNAD can be found at autopsy in $\mathrm{CNC}$ patients in whom no diagnosis of hypercortisolism has been made [3].

\section{Carney Complex}

$\mathrm{CNC}$ is an autosomal dominantly inherited multiple neoplasia syndrome. Along with PPNAD, among the tumors observed in CNC patients are growth hormone secreting pituitary adenomas (acromegaly), thyroid adeno- mas or carcinomas, testicular tumors (large-cell calcifying Sertoli cell tumors), ovarian cysts, melanocytic schwannomas, and breast ductal adenomas (table 1). A cardiac myxoma is also an important manifestation of CNC and could explain the high rate $(10 \%)$ of sudden deaths reported in CNC families [8], underlying the importance of its early diagnosis. An ACTH-independent Cushing syndrome due to PPNAD is observed in $25-30 \%$ of the patients with CNC.

\section{Genetics of $C N C$}

CNC seems to be a genetically heterogeneous disease, and linkage analysis has shown that at least two loci are involved: 2 p16 and 17q22-24. The CNC1 gene located on the $17 \mathrm{q} 22-24$ locus has been identified as the regulatory subunit R1A of protein kinase A (PRKAR1A) [9, 10]. $P R K A R 1 A$ is a key component of the cAMP signaling pathway that has been implicated in endocrine tumorigenesis (fig. 3, 4). Heterozygous inactivating mutations of PRKAR $1 A$ have been reported in about $45 \%$ of the CNC families [18]. In CNC patients with Cushing's syndrome, the frequency of PRKARIA mutations is about $80 \%$, suggesting that families with PPNAD are more likely to be associated with a 17q22-24 defect [19]. Interestingly, patients with isolated PPNAD and no familial history of $\mathrm{CNC}$ can also present a germline de novo mutation of PRKARIA [12]. In the tumors of CNC patients, loss of heterozygosity $(\mathrm{LOH})$ at $17 \mathrm{q} 22-24$ can be observed, suggesting that PRKAR1A is a tumor suppressor gene. Somatic mutation of PRKARIA can occur in PPNAD as a mechanism of inactivation of the wild-type allele in a patient already presenting a germline mutation [12]. However, inactivation of the remaining wild-type allele by genetic alteration seems not a constant step in PPNAD and CNC tumor development [19]. We have reported on a splice site mutation leading to a truncated protein and tumor development without allelic losses in several tumors from the same patient, except in a malignant pancreatic tumor [19]. Similarly, in a mouse transgenic model with heterozygous inactivation of PRKARIA, tumors can develop without allelic loss [20]. This could suggest that the classic model of tumor suppressor gene with a germline inactivating first allelic alteration followed by a second genetic hit leading to inactivation of the remaining wild-type allele might partially be correct for PRKAR1A. In PPNAD, it could also be that a general polyclonal expansion might be stimulated by haploinsufficiency due to the first germline defect; a second genetic hit leading to inactivation of the wild-type allele might further stimulate tumorigenesis and the development of 
adrenocortical nodules. In keeping with this hypothesis the somatic mutation observed in PPNAD in a patient already presenting a germline mutation was found only in a macronodule of $2.5 \mathrm{~cm}$, a diameter unusually high for PPNAD nodules.

Fig. 3. The cAMP signaling pathway from the cell surface to the nucleus: The extracellular ligand (red circle) binds to its specific seven-domain transmembrane receptors (shown in red), leading to activation of a heterotrimeric ( $\alpha, \beta$ and $\gamma$ subunits) Gs protein (shown in yellow). Activation of the Gs protein leads to dissociation of its alpha subunit ( $\alpha \mathrm{s})$ from the $\beta, \gamma$ complex, stimulating adenylyl cyclase activity (AC, shown in green) and, therefore, cAMP production. After binding of cAMP, the PKA (shown in blue) is activated. The free catalytic subunit $(C)$ then enters the nucleus and phosphorylates CREB at serine 133, leading to transactivation.

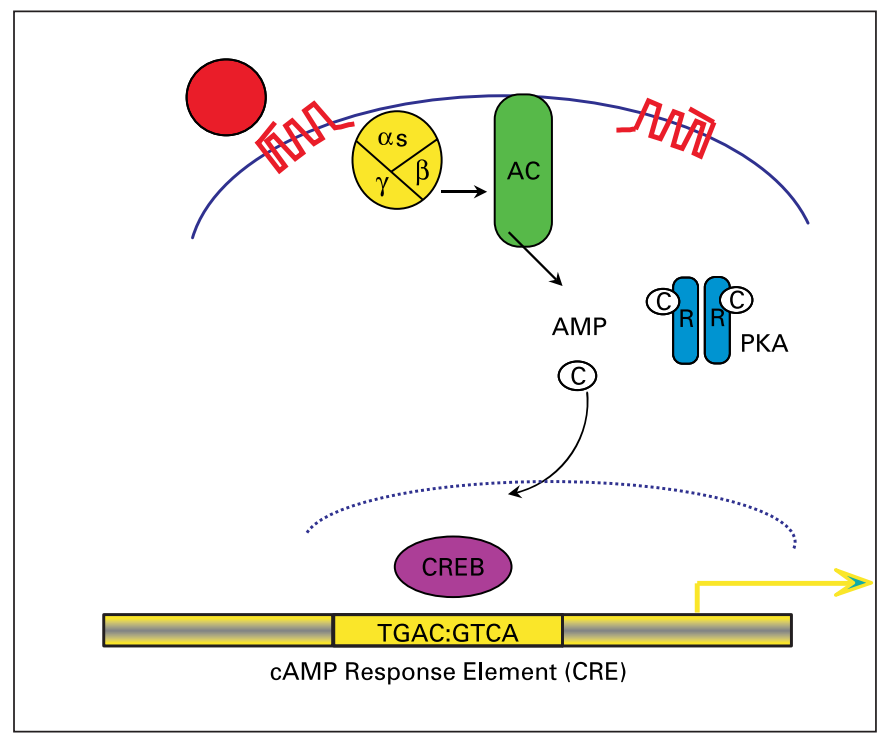

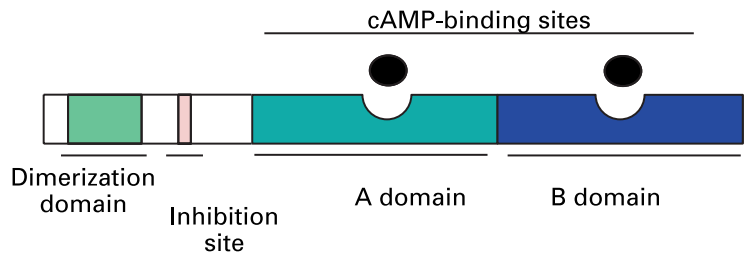

PRKAR1A

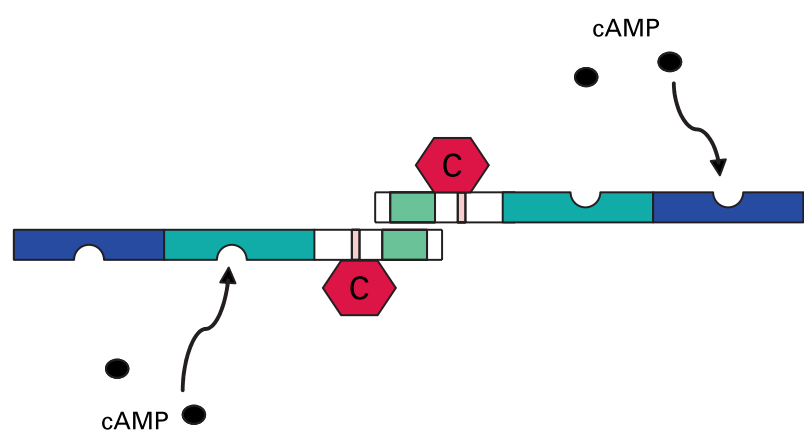

cAMP stimulation
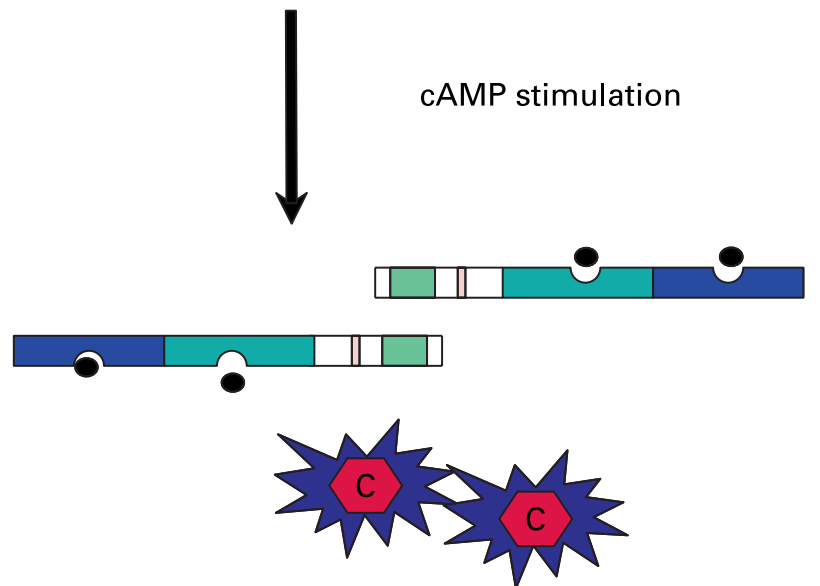

A

B

Fig. 4. cAMP-dependent PKA and its regulatory subunit R1A (PRKAR1A). A Schematic modular structure of $P R K A R 1 A$ with the dimerization domain and the catalytic subunit binding domains on the amino-terminal part and two cAMP-binding sites on the carboxy-terminal part of the protein. B Mechanisms of activation of the PKA heterotetramer after cAMP stimulation. Binding of cAMP to the regulatory subunits leads to dissociation and hence activation of the catalytic subunits $(C$, shown in red). 


\section{CNC1 Gene and Sporadic Adrenocortical Tumors}

In sporadic adrenocortical tumors somatic PRKAR $1 A$ mutations have been found in secreting adrenal adenomas. The adrenal adenomas harboring somatic PRKAR1A mutations present with clinical, hormonal, and pathological features quite similar to PPNAD [21]. These latter adenomas are small tumors responsible for Cushing's syndrome and present a paradoxical rise of cortisol after dexamethasone treatment. Allelic losses ( $\mathrm{LOH})$ at the PRKAR1A locus (17q22-24) have also been observe in sporadic adrenocortical tumors. In adrenocortical adenomas these $\mathrm{LOH}$ seem quite restricted to the PRKAR1A locus, suggesting that this tumor suppressor gene might be involved. By contrast, in adrenocortical cancers $\mathrm{LOH}$ seems to affect a large part of $17 \mathrm{q}$, and PRKAR $1 A$ alteration might play a minor (or no) role in the growth of these tumors.

\section{Unsolved Questions in the Genetics of CNC and PPNAD}

The putative $C N C 2$ gene located at the 2 p16 locus remains to be determined $[8,18]$. However, somatic alterations of the $2 \mathrm{p} 16$ region have been reported in $\mathrm{CNC}$ tumors, even in patients with a mutation of the $\mathrm{CNCl}$ gene (i.e., PRKAR1A located on 17q22-24). These alterations are usually gene amplifications, suggesting a potential oncogene at $2 \mathrm{p} 16$ [22]. In sporadic adrenocortical tumors, 2 p16 amplification has been also reported [22, 23]. Considering the genetics of isolated PPNAD, it should be mentioned that a subgroup of very young pediatric patients might be different from older patients related to CNC. In these patients, the classical finding of pigmented nodules at pathological investigation might be lacking, although micronodules are present, as suggested by the group of Stratakis [13,24]. In this subgroup of very young pediatric cases of PPNAD, Cushing's syndrome might occur between birth and the age of 5 years. The main reason to differentiate this group of PPNAD or PPNAD-like patients is the lower rate of germline-inactivating mutations. In the cohort of patients studied by Bossis and Stratakis [24], germline-inactivating PRKARIA mutations were present in 2 out of 10 patients. In our cohort of 25 patients with isolated PPNAD, the mutation rate of PRKAR $1 A$ is $65 \%$. This rate is lower than in our cohort of patients with CNC (80\%) who present mainly with PPNAD. Interestingly, in the subgroup of patients with isolated PPNAD, in whom Cushing's syndrome was diagnosed before the age of 5 years, we have not found any germline PRKAR $1 A$ mutation $[25,26]$.

\section{PRKAR1A, Protein Kinase A (PKA), and the cAMP Signaling Pathway}

\section{PKA and the cAMP Signaling Pathway}

The cAMP signaling pathway is one of the major transduction pathways that allow extracellular signals to be transmitted into the cell (fig. 3). The PKA is a central component of this pathway. PKA is a tetramer made by two regulatory subunits and two catalytic subunits. Four genes encode the regulatory subunits: PRKARIA and PRKAR $1 B$ and PRKAR2A and PRKAR2B. The CNC gene, $P R K A R 1 A$, is ubiquitously expressed. According to results of initial experiments using elution in Sepharose gel-denaturing anion exchange chromatography, there are two types of PKA activity: PKA-I and PKA-II. It is usually accepted that the regulatory subunits present in the PKA-I activity fractions contain mainly PRKAR $1 A$ and $P R K A R 1 B$. Three genes encode the catalytic subunits $(C \alpha, C \beta$, and $C \gamma)$. Binding of cAMP to its two binding sites on the regulatory subunits leads to dissociation of the catalytic subunits from the regulatory ones, resulting in stimulation of the PKA catalytic activity (fig. 4). Activated PKA can phosphorylate on serine and threonine residues numerous proteins located on the membrane, in the cytoplasm, or, after nuclear entry of the catalytic subunit, in the nucleus. One of the most extensively studied nuclear targets of PKA is the transcription factor CREB (cAMP response element binding protein) that stimulates transcription after PKA phosphorylation [27]. The PKA activity is regulated by cellular trafficking. The A kinase anchoring proteins play a central role in this regulation.

\section{Consequences of PRKAR1A Mutations in CNC and PPNAD}

The consequences of PRKARIA inactivation are currently investigated by several laboratories. Complete inactivation by homologous recombination in animal models is lethal during embryonic life [28]. Mesoderm and heart tube development alterations are observed in the mutant embryo. In these mice an increased basal PKA activity is observed. In heterozygous mice with PRKAR $1 A$ inactivation, it seems that the PKA activity is unaltered [20]. By contrast, in a transgenic mouse model expressing a PRKARIA antisense construct leading to a $60 \%$ decrease of PRKARIA mRNA and protein, the type II PKA activity is increased [29]. In this last model a marked increase of the type II/type I PKA activity is, therefore, observed. The PRKAR $1 A$ antisense expressing mice develop adrenocortical alterations that share some similarities 
Fig. 5. CAMP pathway alterations in various causes of Cushing's syndrome. Alterations of the cAMP pathway at the extracellular $(1,2)$ as well as the intracellular (2-4) levels in various forms of Cushing's syndrome associated with adrenal hyperplasia, adrenal tumors, and macro- or micronodular adrenocortical disease are shown (ACTH-independent macronodular adrenal hyperplasia and PPNAD). It is important to note that (2), (3), and (4) are associated with benign tumors. (1) = Eutopic (Cushing's disease) or ectopic ACTH secretion; (2) = abnormal expression of membrane receptors: GIP (gastric inhibitory peptide) receptor, $\beta$-adrenergic receptor, and luteinizing hormone receptor; $(3)=a c-$ tivating mutation of the alpha subunit of the Gs protein, termed oncogene Gsp in McCune-Albright syndrome, and (4) = inactivating germline mutation of the PRKARIA gene in CNC.

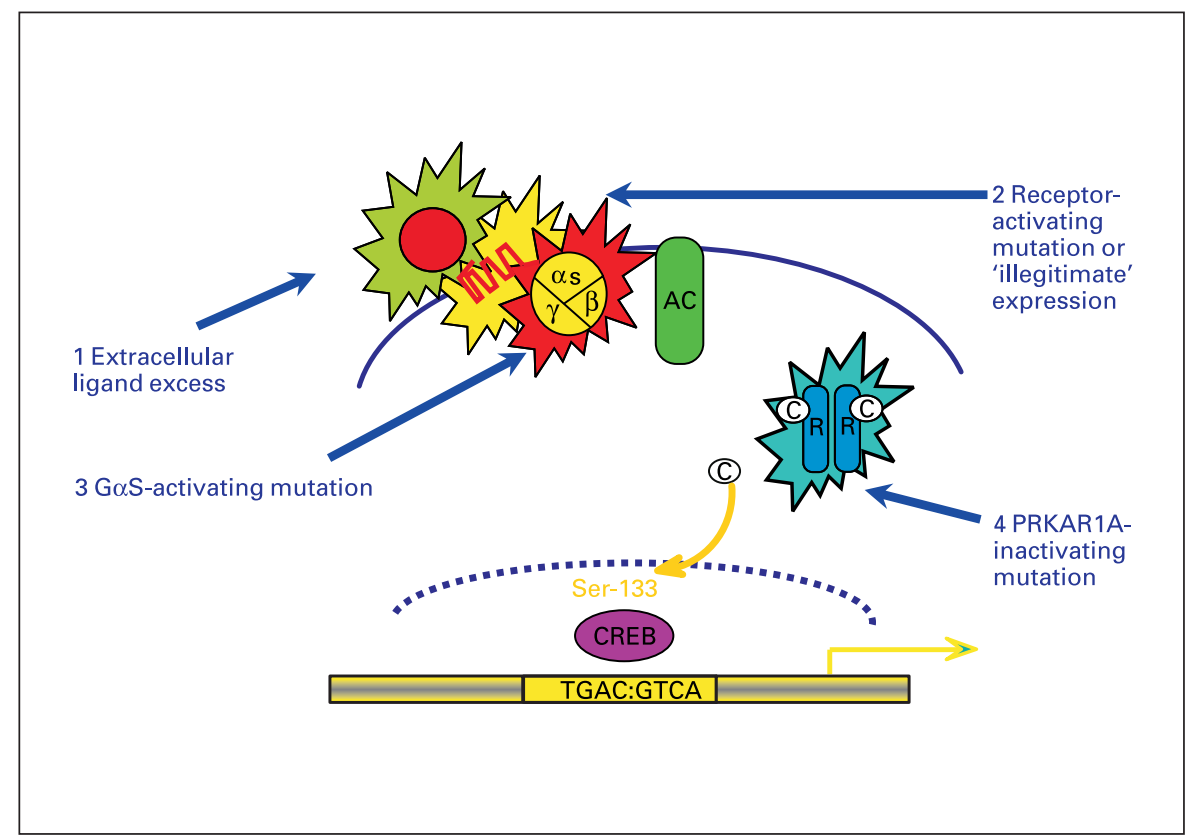

with PPNAD, but with some differences. In the adrenocortical tissue of these mice, pigmentation alone seems not to be different from that of controls, but cortical hyperplasia is observed as well as congestion and $\mathrm{X}$ zone vacuolization [30]. Interestingly, obesity and increased corticosterone levels, both basal and after dexamethasone administration, are observed in these transgenic animals. Adrenocortical tumors from patients with PPNAD exhibit an increased PKA activity in response to cAMP [9] and also an increased type II/type I PKA activity ratio. Similarly, transient transfection of a PRKAR $1 A$ mutant that gives rise to a truncated protein is able to stimulate at the nuclear level the cAMP pathway [19]. In sporadic adrenocortical secreting adrenal adenomas that bear PRKAR1Ainactivating mutation or $17 \mathrm{q} 22-24 \mathrm{LOH}$, an increased PKA activity in response to cAMP is also observed [21]. Despite all these results suggesting alterations of the distal part of the cAMP pathway from PKA to the nucleus after PRKAR1A inactivation, the mechanisms of tumor growth in PPNAD and CNC remain to be determined. It is possible that PRKARIA inactivation exerts some effects on other signaling pathways more frequently involved in tumorigenesis. For instance, ERK2 activation has been observed in lymphocytes from patients with $\mathrm{CNC}$ and PRKAR1A germline mutation [31]. The same alterations of the mitogen-activated protein kinase pathway have been observed in cell lines established from patients with germline PRKAR $1 A$-inactivating mutation.

\section{Conclusions}

The study of the genetics of a rare disease such as CNC allows a better understanding of adrenal Cushing's syndrome and PPNAD, offering also new diagnostic molecular tools. It gives new insights into the mechanisms of endocrine tumorigenesis and adrenal tumor pathophysiology. Interestingly, various other molecular and cellular alterations of the cAMP signaling pathway have been observed in Cushing's syndrome before the identification of the $C N C 1$ gene. The PRKARIA mutation (as shown in figure 5) is just another example of an alteration of this pathway, but interestingly it is so far the most distal component of the cAMP pathway presenting a molecular defect in endocrine tumors.

\section{Acknowledgments}

This work was supported in part by the Ligue National Contre le Cancer (Grant 04-7571) and the GIS-INSERM Institut des Maladies Rares for the Carney Complex Network. 


\section{References}

1 Carney JA, Gordon H, Carpenter PC, Shenoy BV, Go VL: The complex of myxomas, spotty pigmentation, and endocrine overactivity. Medicine (Baltimore) 1985;64:270-283.

$\checkmark 2$ Shenoy BV, Carpenter PC, Carney JA: Bilateral primary pigmented nodular adrenocortical disease: rare cause of the Cushing syndrome. Am J Surg Pathol 1984;8:335-344.

3 Carney JA, Young WF: Primary pigmented nodular adrenocortical disease and its associated conditions. Endocrinologist 1992;2:6-21.

$\checkmark 4$ Meador CK, Bowdoin B, Owen WC, Farmer TA: Primary adrenocortical nodular dysplasia: a rare cause of Cushing's syndrome. J Clin Endocrinol Metab 1967;27:1255-1263.

5 Bricaire H, Luton JP, Ghozland M, Forest M: La polymicroadénomatose de la cortico-surrénale dans le syndrome de Cushing. Ann Med Interne (Paris) 1970;121:755-777.

6 de Gennes JL, Garnier H, Calmette, Malinsky M, Bertrand C: Etude clinique, biologique et histologique d'un cas exemplaire de polymicroadénomatose cortico-surrénale. Ann Endocrinol (Paris) 1970;31:1022-1038.

7 Ruder HJ, Loriaux DL, Lipsett MB: Severe osteopenia in young adults associated with Cushing's syndrome due to micronodular adrenal disease. J Clin Endocrinol Metab 1974;39: 1138-1147.

$>8$ Stratakis CA, Carney JA, Lin JP, Papanicolaou DA, Karl M, Kastner DL, Pras E, Chrousos GP: Carney complex, a familial multiple neoplasia and lentiginosis syndrome. Analysis of $11 \mathrm{kin}-$ dreds and linkage to the short arm of chromosome 2. J Clin Invest 1996;97:699-705.

>9 Kirschner LS, Carney JA, Pack SD, Taymans SE, Giatzakis C, Cho YS, Cho-Chung YS, Stratakis CA: Mutations of the gene encoding the protein kinase A type I-alpha regulatory subunit in patients with the Carney complex. Nat Genet 2000;26:89-92.

10 Casey M, Vaughan CJ, He J, Hatcher CJ, Winter JM, Weremowicz S, Montgomery K, Kucherlapati R, Morton CC, Basson CT: Mutations in the protein kinase A $\mathrm{R} 1$ alpha regulatory subunit cause familial cardiac myxomas and Carney complex. J Clin Invest 2000;106:R31R38.

-11 Stratakis CA, Sarlis N, Kirschner LS, Carney JA, Doppman JL, Nieman LK, Chrousos GP, Papanicolaou DA: Paradoxical response to dexamethasone in the diagnosis of primary pigmented nodular adrenocortical disease. Ann Intern Med 1999;131:585-591.

-12 Groussin L, Jullian E, Perlemoine K, Leheup B, Luton JP, Bertagna X, Bertherat J: Mutations of the PRKAR1A gene in Cushing's syndrome due to sporadic primary pigmented nodular adrenocortical disease (PPNAD). J Clin Endocrinol Metab 2002;87:4324-4329.

13 Gunther DF, Bourdeau I, Matyakhina L, Cassarino D, Kleiner DE, Griffin K, Courkoutsakis N, Abu-Asab M, Tsokos M, Keil M, Carney JA, Stratakis CA: Cyclical Cushing syndrome presenting in infancy: an early form of primary pigmented nodular adrenocortical disease, or a new entity? J Clin Endocrinol Metab 2004;89:3173-3182.
14 Caticha O, Odell WD, Wilson DE, Dowdell LA, Noth RH, Swislocki AL, Lamothe JJ, Barrow R: Estradiol stimulates cortisol production by adrenal cells in estrogen-dependent primary adrenocortical nodular dysplasia. J Clin Endocrinol Metab 1993;77:494-497.

15 Storr HL, Mitchell H, Swords FM, Main KM, Hindmarsh PC, Betts PR, Shaw NJ, Johnston DI, Clark AJ, Reznek RH, Grossman AB, Savage MO: Clinical features, diagnosis, treatment and molecular studies in paediatric Cushing's syndrome due to primary nodular adrenocortical hyperplasia. Clin Endocrinol (Oxf) 2004; 61:553-559.

16 Bourdeau I, Lacroix A, Schurch W, Caron P Antakly T, Stratakis CA: Primary pigmented nodular adrenocortical disease: paradoxical responses of cortisol secretion to dexamethasone occur in vitro and are associated with increased expression of the glucocorticoid receptor. J Clin Endocrinol Metab 2003;88:3931-3937.

17 Sarlis NJ, Chrousos GP, Doppman JL, Carney JA, Stratakis CA: Primary pigmented nodular adrenocortical disease: reevaluation of a patient with Carney complex 27 years after unilateral adrenalectomy. J Clin Endocrinol Metab 1997;82:1274-1278.

18 Kirschner LS, Sandrini F, Monbo J, Lin JP, Carney JA, Stratakis CA: Genetic heterogeneity and spectrum of mutations of the PRKAR1A gene in patients with the Carney complex. Hum Mol Genet 2000;9:30373046.

19 Groussin L, Kirschner L, Vincent-Dejean C, Perlemoine K, Jullian E, Delemer B, Zacharieva $\mathrm{S}$, Pignatelli $\mathrm{D}$, Carney JA, Luton JP, Bertagna X, Stratakis CA, Bertherat J: Molecular analysis of the cyclic AMP-dependent protein kinase $\mathrm{A}$ (PKA) regulatory subunit $1 \mathrm{~A}$ (PRKAR1A) gene in patients with Carney complex and primary pigmented nodular adrenocortical disease (PPNAD) reveals novel mutations and clues for pathophysiology. Am J Hum Genet 2002; 71:1432-1442.

20 Veugelers M, Wilkes D, Burton K, McDermott DA, Song Y, Goldstein MM, La Perle K, Vaughan CJ, O'Hagan A, Bennett KR, Meyer BJ, Legius E, Karttunen M, Norio R, Kaariainen H, Lavyne M, Neau JP, Richter G, Kirali K, Farnsworth A, Stapleton K, Morelli P, Takanashi Y, Bamforth JS, Eitelberger F, Noszian I, Manfroi W, Powers J, Mochizuki Y, Imai T, Ko GT, Driscoll DA, Goldmuntz E, Edelberg JM, Collins A, Eccles D, Irvine AD, McKnight GS, Basson CT: Comparative PRKAR1A genotype-phenotype analyses in humans with Carney complex and prkarla haploinsufficient mice. Proc Natl Acad Sci U S A 2004;101:14222-14227.

-21 Bertherat J, Groussin L, Sandrini F, Matyakhina L, Bei T, Stergiopoulos S, Papageorgiou T, Bourdeau I, Kirschner LS, Vincent-Dejean C, Perlemoine K, Gicquel C, Bertagna X, Stratakis CA: Molecular and functional analysis of PRKAR1A and its locus (17q22-24) in sporadic adrenocortical tumors: $17 \mathrm{q}$ losses, somatic mutations, and protein kinase A expression and activity. Cancer Res 2003;63:5308-5319.
22 Matyakhina L, Pack S, Kirschner LS, Pak E, Mannan P, Jaikumar J, Taymans SE, Sandrini F, Carney JA, Stratakis CA: Chromosome 2 (2p16) abnormalities in Carney complex tumours. J Med Genet 2003;40:268-277.

23 Kjellman M, Roshani L, Teh BT, Kallioniemi OP, Hoog A, Gray S, Farnebo LO, Holst M, Backdahl M, Larsson C: Genotyping of adrenocortical tumors: very frequent deletions of the MEN1 locus in 11q13 and of a 1-centimorgan region in 2 p16. $\mathrm{J}$ Clin Endocrinol Metab 1999;84:730-735

$\checkmark 24$ Bossis I, Stratakis CA: Minireview: PRKAR1A: normal and abnormal functions. Endocrinology 2004; 145:5452-5458.

25 Groussin L, René-Corail F, Jullian E, Bertagna $\mathrm{X}$, Bertherat J: Frequent germline mutation of the PKA regulatory subunit 1 (PRKAR1A) in patients with Carney complex (CNC) and/or sporadic primary pigmented nodular adrenocortical disease (PPNAD). 12th Int Congr of Endocrinology, Lisbon, 2004, 0R46, p 110.

26 Groussin L, Jullian E, René-Corail F, Lefebvre $\mathrm{H}$, Vantyghem MC, Chanson P, Conte-Devolx B, Bertagna X, Bertherat J: A low penetrance mutation in the regulatory subunit R1A of the PKA gene (PRKAR1A) responsible for primary pigmented nodular adrenocortical disease (PPNAD) in seven kindreds suggests a genotype/phenotype correlation in Carney complex (CNC). Endocr Soc 86th Annu Meet, New Orleans, 2004, 0R, pp 10-15.

27 Rosenberg D, Groussin L, Jullian E, Perlemoine K, Bertagna X, Bertherat J: Role of the PKA-regulated transcription factor CREB in development and tumorigenesis of endocrine tissues. Ann N Y Acad Sci 2002;968:65-74.

28 Amieux PS, Howe DG, Knickerbocker H, Lee DC, Su T, Laszlo GS, Idzerda RL, McKnight GS: Increased basal cAMP-dependent protein kinase activity inhibits the formation of mesoderm-derived structures in the developing mouse embryo. J Biol Chem 2002;277:2729427304.

29 Griffin KJ, Kirschner LS, Matyakhina L, Stergiopoulos S, Robinson-White A, Lenherr S, Weinberg FD, Claflin E, Meoli E, Cho-Chung YS, Stratakis CA: Down-regulation of regulatory subunit type $1 \mathrm{~A}$ of protein kinase A leads to endocrine and other tumors. Cancer Res 2004;64:8811-8815.

30 Griffin KJ, Kirschner LS, Matyakhina L, Stergiopoulos S, Robinson-White A, Lenherr S, Weinberg FD, Claflin E, Batista D, Bourdeau I, Voutetakis A, Sandrini F, Meoli EM, Bauer AJ, Cho-Chung YS, Bornstein SR, Carney JA, Stratakis CA: A transgenic mouse bearing an antisense construct of regulatory subunit type 1A of protein kinase A develops endocrine and other tumours: comparison with Carney complex and other PRKAR1A induced lesions. J Med Genet 2004;41:923-931.

-31 Robinson-White A, Hundley TR, Shiferaw M, Bertherat J, Sandrini F, Stratakis CA: Protein kinase-A activity in PRKAR1A-mutant cells, and regulation of mitogen-activated protein kinases ERK1/2. Hum Mol Genet 2003;12: 1475-1484. 